\title{
Reliable cervical anastomosis through the retrosternal route with stepwise gastric tube
}

Yoshifumi Ikeda, MD

Shoichi Tobari, MD

Masanori Niimi, MD, PhD

Shigenao Kan, MD

Hiroshi Takami, MD

Susumu Kodaira, MD

Objectives: An extra-anatomic reconstruction would be beneficial in preventing recurrent malignant dysphagia. A long gastric tube that allowed a sufficient blood flow was necessary to perform the successful cervical anastomosis through the retrosternal route.

Methods: The gastric tube was created by means of separate division and closure of the seromuscular and submucosal-mucosal layers (stepwise group) in 15 consecutive patients and by means of full-thickness cutting of the stomach and closure of the seromuscular layer (standard group) in 22 patients. We compared these 2 types of gastroplasties in terms of total length of the tube, blood flow, and the incidence of anastomotic leakage. Blood flow was measured with a laser Doppler flowmeter during surgical intervention.

Results: The gastric tube in the stepwise group was significantly longer than that in the standard group $(P<.01$, unpaired $t$ test). Tissue blood flow at the site of anastomosis in the stepwise group was significantly greater than that in the standard group $(P<.01$, unpaired $t$ test), and the rate of anastomotic leakage in the stepwise group was significantly lower than that in the standard group $\left(P<.05, \chi^{2}\right.$ test $)$.

Conclusion: We consider this technique to be a useful procedure for retrosternal reconstruction after subtotal esophagectomy.

From the Department of Surgery, Teikyo University School of Medicine, Tokyo, Japan.

Received for publication Feb 1, 2002; revisions requested March 11, 2002; revisions received July 16, 2002; accepted for publication Aug 6, 2002.

Address for reprints: Yoshifumi Ikeda, MD, Department of Surgery, Teikyo University School of Medicine, 2-11-1 Kaga, Itabashi-ku, Tokyo 173-8605, Japan (Email: yikeda@med.teikyo-u.ac.jp).

J Thorac Cardiovasc Surg 2003;125: 1306-12

Copyright $\odot 2003$ by The American Association for Thoracic Surgery

$0022-5223 / 2003 \$ 30.00+0$

doi:10.1016/S0022-5223(02)73407-7

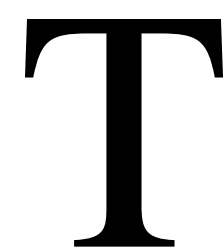

he majority of patients with esophageal carcinoma die from recurrent malignant disease, even when operated on with curative intent. In approximately one third of these patients, the recurrence is located in the operative field. ${ }^{1-3}$ When esophageal substitutes are placed in the anatomic prevertebral position, recurrent intrathoracic locoregional tumor masses invade the neo-esophagus and might cause recurrent malignant dysphagia. ${ }^{4}$ The dysphagia could be prevented if an extra-anatomic reconstruction, such as through the retrosternal or subcutaneous route, were used. However, the extra-anatomic route might increase the rate of anastomotic leakage.

The stomach, colon, or jejunum can be used for esophageal reconstruction after esophagectomy, but the stomach is used most commonly. After gastric mobilization and formation of a gastric tube, the proximal stomach is vascularized by an intramural plexus of vessels and branches from the right gastroepiploic artery, and the anastomotic site is the most distal site in the gastric tube from its blood supply. ${ }^{5-7}$ Moreover, the gastric tube to be brought up to the neck from the abdomen must be of sufficient length. ${ }^{8}$ A review of more than a hundred esophagectomy cases suggests that successful cervical anastomosis through the extra-anatomic route requires a long gastric tube with adequate blood flow. 

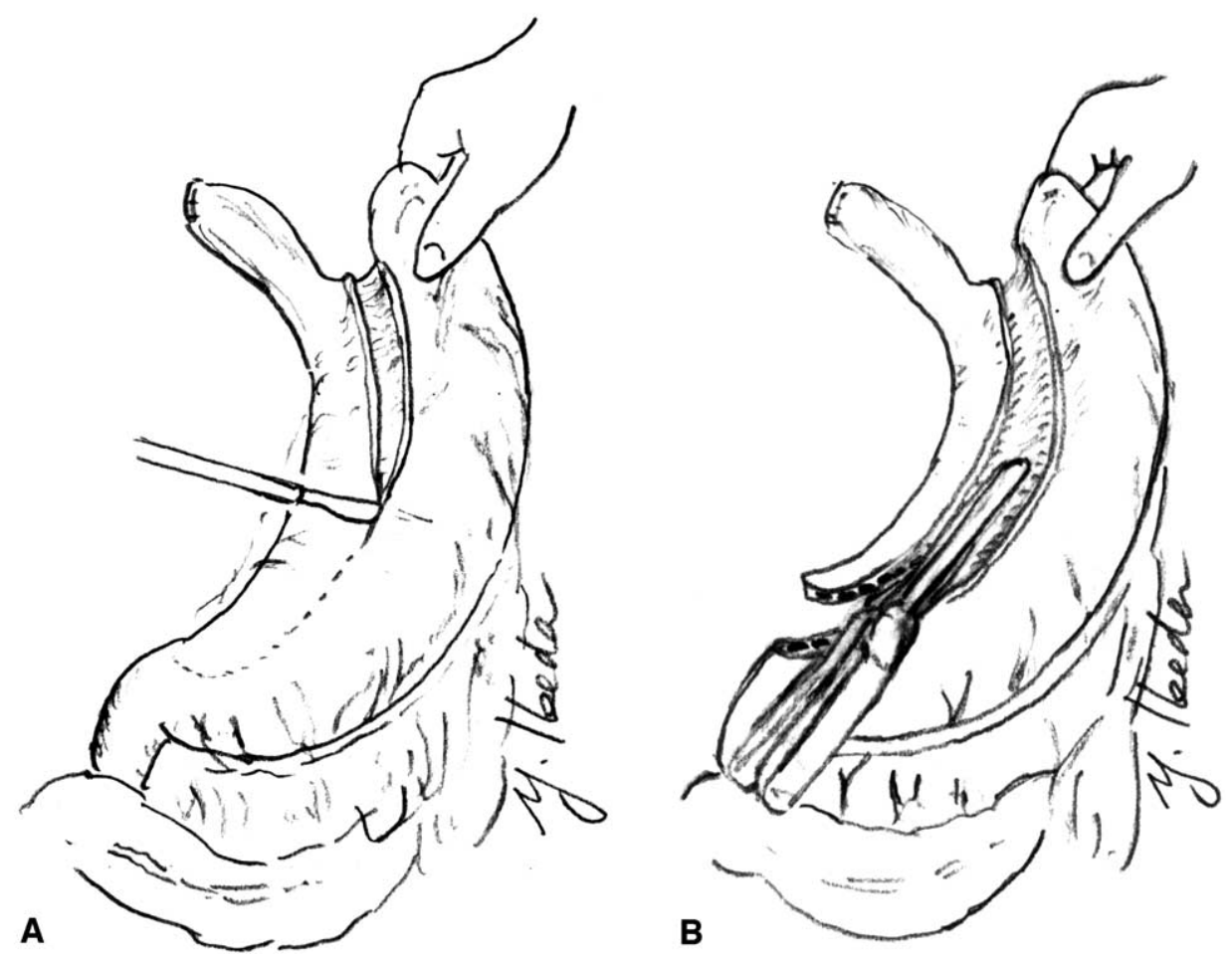

Figure 1. In stepwise gastroplasty, only the seromuscular layer was incised along a curved line parallel to the greater curvature (A). Then, the lesser curvature was extirpated by dividing the remaining mucosal layer with the suturing device (B).

We devised a procedure that involves separate division and closure of the seromuscular and submucosal-mucosal layers along the greater curvature to obtain a gastric tube of greater effective length. In this study this new technique of preparing the gastric tube was evaluated by comparing stepwise gastric tube construction with standard gastric tube construction.

\section{Patients and Methods}

\section{Patients}

In the 5 years from 1996 to 2000, subtotal esophagectomy with retrosternal cervical esophagogastrostomy was performed to treat 37 cases of intrathoracic esophageal carcinoma without clinical evidence of any risk to cardiac function, pulmonary function, or both at Teikyo University Hospital. There were 31 men and 6 women in the study aged 39 to 85 years (mean, 63 years). None of the patients had received preoperative chemotherapy or radiotherapy. Total thoracic esophagectomy with regional lymphadenectomy and reconstruction was performed by means of right thoracotomy, laparotomy, and cervicotomy in 30 patients and by means of transhiatal blunt dissection without thoracotomy in the other 7 patients. The indications for transhiatal blunt dissection included superficial carcinoma or age over 80 years. Curative esophagectomy was performed in every case. The same nutritional protocol was used in all patients.

A procedure that involves separate cutting of the seromuscular and mucosal layers was performed in 15 consecutive patients between May 1998 and December 2000 (stepwise group), and a procedure that involves full-thickness cutting of the stomach was carried out in 22 patients between January 1996 and April 1998 (standard group). There were no differences in preoperative, operative, or postoperative management between the 2 groups.

\section{Construction of the Gastric Tube}

After mobilizing the stomach by means of ligation of the left gastric artery, left gastroepiploic artery, and short splenic artery, the gastric tube was constructed by preserving the first 3 branches of the right gastric artery and fashioned along the greater curvature. In the stepwise group only the seromuscular layer was incised along a curved line parallel to and $4 \mathrm{~cm}$ from the greater curvature (Figure 1,A). After completion of the seromuscular cut, the gastric tube was stretched as far as possible. Next, the lesser curvature was extirpated by dividing the remaining mucosal layer with a GIA (Auto Suture, United States Surgical Corp, Norwalk, Conn) or linear stapler (Johnson \& Johnson Medical; Figure 1, B). The seromuscular layer was closed in interrupted fashion with Lembert sutures. In the standard group, after stretching the stomach as far as possible, the full thickness of the stomach was divided along a curved line parallel to and $4 \mathrm{~cm}$ from the greater curvature with a GIA or linear stapler (Figure 2). The seromuscular layer was closed in interrupted fashion with Lembert sutures.

\section{Cervical Anastomosis}

The gastric tube was brought up to the neck through the retrosternal route. A purse-string suture was placed at end of the esopha- 


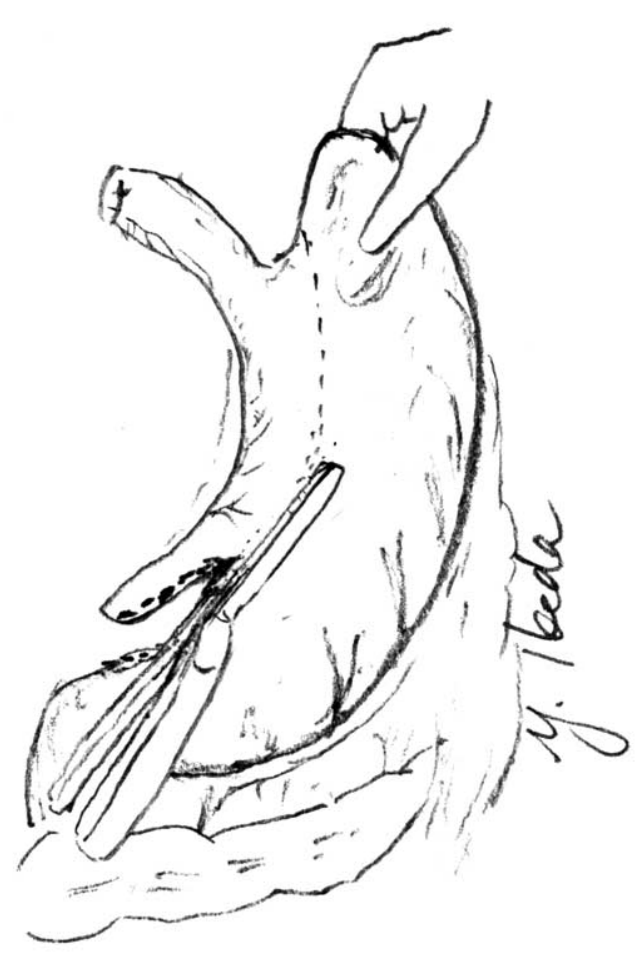

Figure 2. In standard gastroplasty, after the stomach was stretched as far as possible, the full thickness of the stomach was divided along a curved line parallel to the greater curvature with the suturing device.

gus, and the anvil was advanced into the esophageal lumen. The purse-string suture was then tied around the anvil. A circular stapling device was introduced through the gastrotomy at the top of the gastric tube and passed through its posterior wall. Finally, the anvil and stapler were approximated, and the instrument was fired (Figure 3). The gastrotomy was then closed with a GIA or linear stapler.

Cervical anastomosis was in performed all patients by using the same technique with a 25-mm circular stapling device, such as the EEA (Auto Suture) or ILS (Johnson \& Johnson Medical). Heineke-Mikulicz pyloroplasty was performed in all cases.

\section{Length of the Stomach, Gastric Tube, and Anastomotic Site}

After the stomach was mobilized, the distance between the site of the pylorus and the top of the stomach was measured. The gastric tube was then constructed by using each of the procedures, and the distance between the site of the pylorus and the top of the gastric tube was again measured. The gastric tube was then brought up to the neck through the retrosternal route, and the distance between the site of anastomosis and the top of the gastric tube was measured.

\section{Tissue Blood Flow of the Gastric Tube}

Blood perfusion of the gastric tubes was measured with a helium-neon (HeNe) laser Doppler flowmeter (model ALF21; Advanced Laser Flowmeter Corp, Tokyo, Japan). The laser light was guided to the

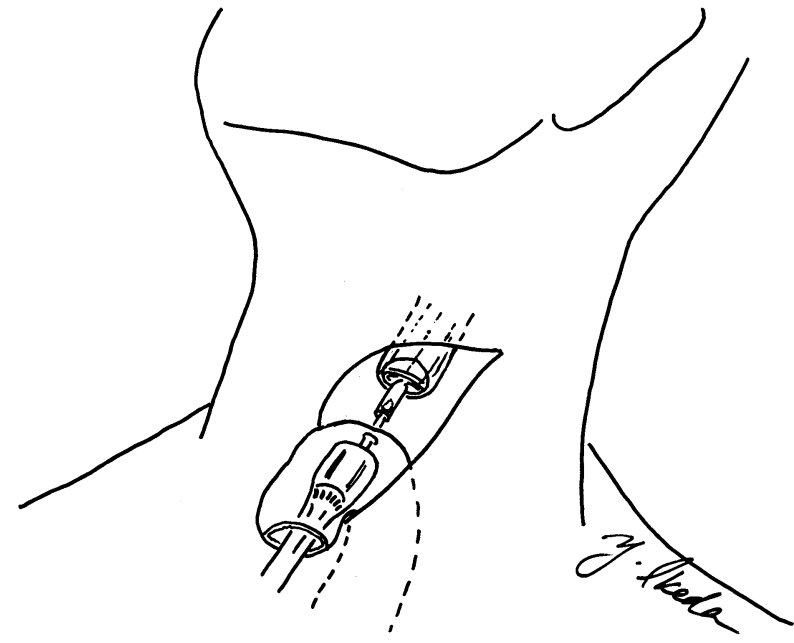

Figure 3. A circular stapling device was introduced through the gastrotomy at the top of the gastric tube and passed through the posterior wall of the gastric tube. The anvil and stapler were then approximated, and the instrument was fired.

tissue, and backscattered light was detected with a master probe (type $\mathrm{S}$, Advanced Laser Flowmeter Corp). This method relies on measurement of Doppler frequency shifts in laser light reflected from moving red blood cells, and the results are displayed after conversion to units in milliliters per minute per $100 \mathrm{~g}$ on the basis of the theory proposed by Bonner. ${ }^{9}$ Laser Doppler flowmetry at the gastric tube was performed during the operation. Each measurement was made for 30 seconds, and the procedure was repeated. The mean of the 2 values was used as tissue blood flow (TBF).

The first measurements of $\mathrm{TBF}$ were made after gastric tube construction along the greater curvature. TBF was measured at $1-\mathrm{cm}$ intervals, and from the top of the gastric tube, it was measured for $5 \mathrm{~cm}$. Then, the gastric tube was brought up to the neck through the retrosternal route. The second measurements were made at the neck after performing esophagogastrostomy. TBF was measured at the anastomotic site (TBFa) of the gastric tube, the nearest point along the anastomotic line from the top of the gastric tube chosen as the site of the measurements.

Leakage of the anastomosis was defined as a salivary fistula or was detected by means of contrast esophagography 7 to 10 days postoperatively.

\section{Statistical Analysis}

Patient groups were compared by means of the $\chi^{2}$ test, the paired $t$ test, and the unpaired $t$ test with Stat View software (SAS Institute Inc, Cary, NC). Variables that demonstrated an important difference comparing patients without and with anastomotic leakage were examined with multivariable analysis. Values were expressed as means $\pm \mathrm{SD}$.

\section{Results}

\section{Patient Profiles}

The mean age, sex ratio, preoperative serum albumin concentration, hemoglobin level, and pathologic stage accord- 
TABLE 1. Characteristics of the 2 patient groups

\begin{tabular}{lccc}
\hline & $\begin{array}{c}\text { Stepwise group } \\
\text { (n = 15) }\end{array}$ & $\begin{array}{c}\text { Standard group } \\
(\mathbf{n}=\mathbf{2 2})\end{array}$ & $\boldsymbol{P}$ value \\
\hline Sex & & & \\
$\quad$ Male & 13 & 18 & NS \\
$\quad$ Female & 2 & 4 & \\
Age (y) & $64.3 \pm 10.3$ & $62.3 \pm 9.9$ & NS \\
& $(45-83)$ & $(39-85)$ & \\
Serum albumin $(\mathrm{g} / \mathrm{dL})$ & $3.7 \pm 0.1$ & $3.8 \pm 0.2$ & $\mathrm{NS}$ \\
Hemoglogin $(\mathrm{g} / \mathrm{dL})$ & $13.3 \pm 0.3$ & $13.0 \pm 0.4$ & $\mathrm{NS}$ \\
p Stage* & & & \\
I & 1 & 2 & $\mathrm{NS}$ \\
IIA & 6 & 10 & \\
IIB & 4 & 6 & \\
III & 4 & 4 & \\
\hline
\end{tabular}

NS, Statistically not significant.

*According to clinical stage on the basis of TNM classification after resection.

ing to the TNM classification of the esophagus ${ }^{10}$ after resection did not differ between the 2 groups (Table 1). There were no differences in operation method or type of circular stapling device used between the 2 groups. Although patients in the separate cutting group had a longer operating time and more blood loss than the patients in the full-thickness cutting group, the differences between the 2 groups were not significant (Table 2).

\section{TBF Measurement}

Pulse rate, mean arterial pressure, central venous pressure, and oxygen saturation were monitored during the operation. $\mathrm{PaO}_{2}$ was measured once an hour. There were no significant differences in these parameters between the 2 TBF measurement points. The difference between measurements repeated twice was $0.30 \pm 0.22 \mathrm{~mL} / \mathrm{min}$ per $100 \mathrm{~g}$, and they varied under $1.0 \mathrm{~mL} / \mathrm{min}$ per $100 \mathrm{~g}$ in this study.

\section{Total Length of the Gastric Tube}

The average length of the stomach was $29.4 \pm 2.9 \mathrm{~cm}$ in the stepwise group and $29.8 \pm 3.2 \mathrm{~cm}$ in the standard group. There was no difference in the length of the stomach between the 2 groups. After construction of the gastric tube, the average length of the gastric tube was $38.4 \pm 3.5 \mathrm{~cm}$ in the stepwise group and $33.5 \pm 3.7 \mathrm{~cm}$ in the standard group. The gastric tube was significantly longer than the stomach. The elongation method used in the stepwise group made the gastric tube an average of $5 \mathrm{~cm}$ longer than the method in standard group (Table 3).

\section{Changes in TBF in the Gastric Tube}

TBF at $1-\mathrm{cm}$ intervals from the top of the gastric tube gradually increased from $8.8 \pm 3.4$ to $15.3 \pm 4.9 \mathrm{~mL} / \mathrm{min}$ per $100 \mathrm{~g}(P<.01$, paired $t$ test $)$ in the stepwise group and from $8.1 \pm 2.5$ to $15.0 \pm 3.6 \mathrm{~mL} / \mathrm{min}$ per $100 \mathrm{~g}(P<.01$,
TABLE 2. Operative factors of the 2 patient groups

\begin{tabular}{|c|c|c|c|}
\hline & $\begin{array}{l}\text { Stepwise group } \\
\quad(\mathrm{n}=15)\end{array}$ & $\begin{array}{l}\text { Standard group } \\
\quad(\mathrm{n}=22)\end{array}$ & $P$ value \\
\hline \multicolumn{4}{|l|}{ Operative method } \\
\hline Right thoracotomy & 12 & 18 & NS \\
\hline Blunt dissection & 3 & 4 & \\
\hline \multicolumn{4}{|l|}{ Circular stapling device } \\
\hline EEA & 10 & 14 & NS \\
\hline ILS & 5 & 8 & \\
\hline Operation time (min) & $376 \pm 54$ & $348 \pm 45$ & NS \\
\hline Blood loss (mL) & $674 \pm 186$ & $577 \pm 175$ & NS \\
\hline
\end{tabular}

TABLE 3. Postoperative course of the two patient groups

\begin{tabular}{lccr}
\hline & $\begin{array}{c}\text { Stepwise group } \\
\text { (n= 15) }\end{array}$ & $\begin{array}{c}\text { Standard group } \\
(\mathbf{n}=\mathbf{2 2})\end{array}$ & $\boldsymbol{P}$ value \\
\hline $\begin{array}{l}\text { Length of stomach (cm) } \\
\text { Length of gastric tube }\end{array}$ & $29.4 \pm 2.9$ & $29.8 \pm 3.8$ & $\mathrm{NS}^{*}$ \\
$\quad$ (cm) & $38.4 \pm 3.5$ & $33.5 \pm 3.7$ & $<.01^{*}$ \\
$\begin{array}{l}\text { Distance between } \\
\text { anastomosis and top } \\
\text { of gastric tube (cm) }\end{array}$ & $7.0 \pm 1.8$ & $3.7 \pm 1.2$ & $<.01^{*}$ \\
$\begin{array}{l}\text { TBFa after anastomosis } \\
\text { (mL/min per 100 g) }\end{array}$ & $16.5 \pm 2.2$ & $11.9 \pm 3.2$ & $<.01^{*}$ \\
$\begin{array}{l}\text { Anastomotic leakage } \\
\text { Complications without } \\
\text { anastomotic leakage }\end{array}$ & $0(0 \%)$ & $5(23 \%)$ & $<.05 \dagger$ \\
\hline
\end{tabular}

$N S$, Statistically not significant.

${ }^{*}$ Student $t$ test.

$\dagger \chi^{2}$ test.

paired $t$ test) in the standard group. There was no statistically significant difference between the stepwise group and standard group in TBF at the same distances from the top of the gastric tube (Figure 4).

Site of the Anastomosis and TBFa After Anastomosis

The distances between the site of anastomosis and the top of the gastric tube in the stepwise and standard groups were 7.0 $\pm 1.8 \mathrm{~cm}$ and $3.7 \pm 1.2 \mathrm{~cm}$, respectively. Length in the stepwise group was significantly greater than that in the standard group (Table 3). TBFa after anastomosis was 16.5 $\pm 2.2 \mathrm{~mL} / \mathrm{min}$ per $100 \mathrm{~g}$ in the stepwise group and $11.9 \pm$ $3.2 \mathrm{~mL} / \mathrm{min}$ per $100 \mathrm{~g}$ in the standard group. TBFa after anastomosis in the stepwise group was significantly higher than that in the standard group $(P<.01$, unpaired $t$ test; Table 3).

Leakage Versus Method of Construction of the Gastric Tube

No anastomotic leakage was observed in the stepwise group, but anastomotic leakage occurred in 5 patients in the 


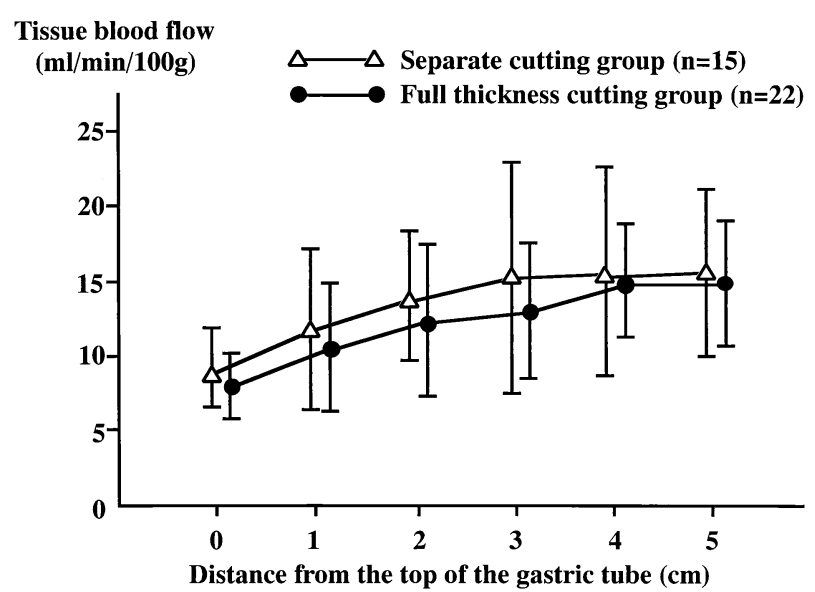

Figure 4. Changes of TBF at 1-cm intervals from the top of the gastric tube. There was no statistical difference in TBF at the same distances from the top of the gastric tube between the stepwise group and standard group.

standard group (22.7\%, $P<.05$; Table 3). Postoperative complications without anastomotic leakage did not differ between the 2 groups (Table 3). Three anastomotic leakages were diagnosed as a salivary fistula, and 2 were detected by means of contrast esophagography. All leakages healed spontaneously with conservative management. Of the 7 demographic and clinicopathologic characteristics analyzed with the multivariate analysis, the method of construction of the gastric tube was the important independent variable $(P$ $=.04121$, Table 4).

\section{Discussion}

Anastomotic leakage is one of the most hazardous complications of esophagogastrostomy for intrathoracic esophageal carcinoma. ${ }^{11,12}$ Although leakage is more frequent through the retrosternal route with cervical anastomosis than after thoracic anastomosis or through the posterior mediastinal reconstruction, ${ }^{8,13}$ malignant dysphagia caused by intrathoracic locoregional tumor recurrence was avoided because the gastric tube runs away from the site of recurrence. ${ }^{1,4}$ Several factors that influence the risk of local and regional recurrence have been identified. Regional mediastinal recurrences are associated more with the extent of lateral spread of the primary tumor and with lymphatic and blood vessel invasion. In advanced carcinoma of the thoracic esophagus, we selected extra-anatomic reconstruction with cervical anastomosis. ${ }^{13}$

Inadequate nutrition, neoplastic permeation of the anastomotic cut margin, technical errors in the anastomosis, insufficient blood flow in the gastric fundus, and tension on the anastomotic site were associated with a higher incidence of anastomotic leakage. ${ }^{14}$ Of these factors, insufficient blood flow and a tension on the gastric tube are the most
TABLE 4. Results of multivariate analysis for anastomotic leakage

\begin{tabular}{lrcc}
\hline Variable & $\begin{array}{c}\text { Regression } \\
\text { coefficient }\end{array}$ & Relative risk (95\% CI) & $\boldsymbol{P}$ value \\
\hline Age & -0.004 & $0.006(-0.016$ to 0.007) & .4459 \\
Sex (F/M) & -0.182 & $0.157(-0.504$ to 0.140) & .2570 \\
p Stage* (I/IIA/IIB/III) & 0.067 & $0.061(-0.059$ to 0.192) & .2860 \\
$\begin{array}{l}\text { Year of operation } \\
\text { Operative method } \\
\quad \text { (right thoracotomy/ }\end{array}$ & 0.093 & $0.075(-0.061$ to 0.247) & .2278 \\
$\quad$ blunt dissection) & & $0.139(-0.165$ to 0.403) & .3983 \\
$\begin{array}{c}\text { Complications without } \\
\quad \text { leakage (+/-) }\end{array}$ & -0.019 & $0.119(-0.263$ to 0.225) & .8731 \\
$\begin{array}{c}\text { Construction of } \\
\quad \text { gastric tube }\end{array}$ & -0.471 & $0.221(-0.922$ to -0.020$)$ & .0412 \\
$\quad$ (stepwise/standard) & & & \\
\hline
\end{tabular}

${ }^{*}$ According to clinical stage based on the TNM classification after resection.

important. ${ }^{5-7,9,12,13,15}$ Successful cervical anastomosis through the retrosternal route required a long gastric tube with sufficient blood flow. ${ }^{13}$

In this study we devised a procedure in which the seromuscular and mucosal layers are divided and sutured separately. Seromuscular cutting facilitates elongation of the gastric tube and releases the mucosal-seromuscular structural connection. The gastric tube in the stepwise group was significantly longer than that in the standard group, and elongation of the gastric tube was approximately $5 \mathrm{~cm}$. We used measurement of TBF by means of laser Doppler flowmetry to estimate the degree of vascularization of the gastric tube. This technique is simple and noninvasive, and when the master probe is used, there are few movement artifacts, and the pressure between the surface and probe is constant. The reliability of the double measurements of TBF varied within a range of less than $1.0 \mathrm{~mL} / \mathrm{min}$ per $100 \mathrm{~g}$ in our study. Conflicting evidence suggests that blood flow at depths of between 1 and $6 \mathrm{~mm}$ is measured by means of laser Doppler flowmetry, ${ }^{16}$ and it is not known whether blood flow on the mucosal side of the stomach is detected by means of measurement on the serosal side. There is autoregulation of mucosal perfusion at high gastric flow rates, but at lower flow rates, mucosal perfusion enjoys a linear relationship with total arterial flow. ${ }^{17,18}$ As a result, the reduction of arterial flow in a gastric tube causes the gastric mucosa to lose its autoregulatory ability, and serosal and mucosal perfusion become parallel to each other. ${ }^{16} \mathrm{We}$ also demonstrated a correlation between mucosal and serosal perfusion after mobilization of the gastric tube ${ }^{19}$ and reported that very low TBF levels might be an important indicator of potential leakage. ${ }^{13}$

Although we obtained longer gastric tubes in the stepwise group than in the standard group, TBF at $1-\mathrm{cm}$ inter- 
vals from the top of the gastric tube increased gradually over $5 \mathrm{~cm}$, and TBF at the same distance from the top of the gastric tube was maintained. When the gastric tube was brought up to the neck through the retrosternal route, this technique allowed anastomosis at a lower site on the gastric tube without tension, and improvement of TBFa after the anastomosis decreased the rate of anastomotic leakage. Several procedures have been reported to improve the perfusion at the anastomotic site of gastric tubes. ${ }^{15,20,21}$ Additional microvascular anastomosis is one of the useful techniques. ${ }^{15,21}$ Murakami and associates ${ }^{15}$ reported significant increases both after venous anastomosis alone and after arterial and venous anastomosis. Their data demonstrated a $36 \%$ increase in TBF after venous anastomosis, and the postoperative course after venous anastomosis and both arterial and venous anastomosis was similar. They emphasized that venous anastomosis alone was adequate to obtain sufficient blood flow to prevent anastomotic leakage.

Our technique was followed by a significant increase in mean TBFa after anastomosis, from 11.9 to $16.5 \mathrm{~mL} / \mathrm{min}$ per $100 \mathrm{~g} \mathrm{(38 \%} \mathrm{increase),} \mathrm{and} \mathrm{TBFa} \mathrm{after} \mathrm{anastomosis} \mathrm{in} \mathrm{the}$ stepwise group was sufficient to prevent anastomotic leakage. The rate of anastomotic leakage in the stepwise group was $0 \%$, and this was significantly lower than the rate in the standard group. Because our study had small numbers of patients operated on over a long time interval, general improvements in perioperative care, nutrition, operative experience, and other factors might influence the incidence of anastomotic leakage in addition to our technique. In this study the same nutritional protocol was used in all patients. Moreover, patients' characteristics, operative factors, and postoperative complications without anastomotic leakage did not differ between the 2 groups. Among independent variable factors, including year of operation, the method of construction of the gastric tube was the most important according to the multivariate analysis.

Any surgeon can easily perform our procedure in about 30 minutes, whereas revascularization with a special technique for vascular anastomosis under a surgical microscope requires approximately 2 hours. ${ }^{15,21}$ Although several novel anastomotic techniques have been devised to prevent anastomotic complications, ${ }^{22,23}$ our technique for creating a long gastric tube with sufficient blood flow also allows safe performance of cervical anastomosis through the retrosternal route.

\section{Conclusion}

Esophagectomy is one of the most extensive gastrointestinal surgical procedures. Reducing the risk of anastomotic complications is essential for a better prognosis. Our new technique was clearly demonstrated by 2 clinically important observations. First, the gastric tube in the stepwise group was significantly longer than that in the standard group. Second, TBF at $1-\mathrm{cm}$ intervals from the top of the gastric tube increased gradually over $5 \mathrm{~cm}$, and TBF at the same distance from the top of the gastric tube in the stepwise group was maintained to that in the standard group. Therefore, stepwise construction of the gastric tube provided a longer tube and allowed anastomosis to be performed at a site lower on the gastric tube. This technique allows the anastomosis to be performed at a tension-free anastomotic line with better blood flow on the gastric tube, and anastomotic leakage was significantly decreased. We consider this technique to be a useful procedure for reconstruction through the retrosternal route after subtotal esophagectomy for intrathoracic esophageal carcinoma.

\section{References}

1. van Lanschot JJ, Tilanus HW, Voormolen $\mathrm{MH}$, van Deelen RA. Recurrence pattern of oesophageal carcinoma after limited resection does not support wide local excision with extensive lymph node dissection. Br J Surg. 1994;81:1320-3.

2. Fahn HJ, Wang LS, Huang BS, Huang MH, Chien KY. Tumor recurrence in long-term survivors after treatment of carcinoma of the esophagus. Ann Thorac Surg. 1994;57:669-76.

3. Law SYK, Fok M, Wong J. Pattern of recurrence after oesophageal resection for cancer: clinical implications. Br J Surg. 1996;83:107-11.

4. van Lanschot JJ, Hop WC, Voormolen MH, van Deelen RA, Blomjous JG, Tilanus HW. Quality of palliation and possible benefit of extraanatomic reconstruction in recurrent dysphagia after resection of carcinoma of the esophagus. J Am Coll Surg. 1994;179:705-13.

5. Pierie JP, De Graaf PW, Poen H, Van der Tweel I, Obertop H. Impaired healing of cervical oesophagogastrostomies can be predicted by estimation of gastric serosal blood perfusion by laser Doppler flowmetry. Eur J Surg. 1994;160:599-603.

6. Korenaga D, Toh Y, Maekawa S, Ikeda T, Sugimachi K. Intraoperative measurement of the tissue blood flow for evaluating blood supply to the gastric tube for esophageal reconstruction. Hepatogastroenterology. 1998;45:2179-80.

7. Boyle NH, Pearce A, Hunter D, Owen WJ, Mason RC. Intraoperative scanning laser Doppler flowmetry in the assessment of gastric tube perfusion during esophageal resection. J Am Coll Surg. 1999;188:498502.

8. Lee Y, Fujita H, Yamana H, Kakegawa T. Factors affecting leakage following esophageal anastomosis. Surg Today. 1994;24:24-9.

9. Bonner RF, Clem TR, Bown PD. Laser-Doppler continuous real-time monitor of pulsatile and mean blood flow in tissue microcirculation. In: Chen SH, Chu B, Nossal R, eds. Scattering techniques applied to supramolecular and nonequilibrium systems. New York: Plenum; 1981. p. 685-701.

10. Hermanek $P$, Sobin LH, International Union Against Cancer (UICC). TNM classification of malignant tumors. 4th ed. 2nd revision. Berlin: Springer; 1992.

11. Urschel JD. Esophagogastric anastomosis leaks complicating esophagectomy: a review. Am J Surg. 1995;169:634-40.

12. Anikin VA, McManus KG, Graham AN, McGuigan JA. Total thoracic esophagectomy for esophageal cancer. J Am Coll Surg. 1997;185: 525-9.

13. Ikeda Y, Niimi M, Kan S, Shatari T, Takami H, Kodaira S. Clinical significance of tissue blood flow during esophagectomy by laser Doppler flowmetry. J Thorac Cardiovasc Surg. 2001;122:1101-6.

14. Peracchia A, Bardini R, Ruol A, Asolati M, Scibetta D. Esophagovisceral anastomotic leak: a prospective statistical study of predisposing factors. J Thorac Cardiovasc Surg. 1988;95:685-91.

15. Murakami M, Sugiyama A, Ikegami T, Ishida K, Maruta F, Shimizu F, et al. Revascularization using the short gastric vessels of the gastric tube after subtotal esophagectomy for intrathoracic esophageal carcinoma. J Am Coll Surg. 2000;190:71-7.

16. Wardell K, Jakobsson A, Nilsson GE. Laser Doppler perfusion imag- 
ing by dynamic light scattering. IEEE Trans Biomed Eng. 1993;40: 309-13.

17. Kiel JW, Riedel GL, Shepherd AP. Autoregulation of canine gastric mucosal blood flow. Gastroenterology. 1987;93:12-20.

18. Boyle NH, Pearce A, Hunter D, Owen WJ, Mason RC. Scanning laser Doppler flowmetry and intraluminal recirculating gas tonometry in the assessment of gastric and jejunal perfusion during oesophageal resection. Br J Surg. 1998;85:1407-11.

19. Hanashi T. An experimental study on circulation in stomach roll by laser-Doppler flowmetry. Teikyo Med J. 1997;20:135-47.

20. Ueo $\mathrm{H}$, Abe R, Takeuchi H, Arinaga S, Akiyoshi T. A reliable operative procedure for preparing a sufficiently nourished gastric tube for esophageal reconstruction. Am J Surg. 1993;165:273-6.

21. Nagawa H, Seto Y, Nakatsuka T, Kaizaki S, Muto T. Microvascular anastomosis for additional blood flow in reconstruction after intrathoracic esophageal carcinoma surgery. Am J Surg. 1997;173:131-3.

22. Orringer MB, Marshall B, Iannettoni MD. Eliminating the cervical esophagogastric anastomotic leak with a side-to-side stapled anastomosis. J Thorac Cardiovasc Surg. 2000;119:277-88.

23. Narendar M, Gupta MS, Rajesh Gupta MS, Manikyam S, Rao MS, Vikas Gupta MS. Minimizing cervical esophageal anastomotic complications by a modified technique. Am J Surg. 2001;181:534-9.

\section{Online-www.aats.org}

Now you can get The Journal of Thoracic and Cardiovascular Surgery online. The Journal online brings you faster delivery time, easy searching of current and back issues, links to PubMed, AATS, WTSA, and other important sites, and more. Visit the Journal online today.

\section{Receive tables of contents by e-mail}

To receive the tables of contents by e-mail, sign up through our Web site at http://www.mosby.com/jtcvs

Choose E-mail Notification

Simply type your e-mail address in the box and click the Subscribe button.

Alternatively, you may send an e-mail message to majordomo@mosby.com.

Leave the subject line blank and type the following as the body of your message: subscribe jtcvs_toc

You will receive an e-mail to confirm that you have been added to the mailing

list.

Note that TOC e-mails will be sent out when a new issue is posted to the Web site. 